\title{
Stakeholders Perception of Success: an Empirical Investigation
}

\author{
Evgenia Egorova, \\ Marco Torchiano, \\ Maurizio Morisio \\ Politecnico di Torino \\ Turin, Italy \\ \{eugenia.egorova, torchiano, \\ morisio\}@polito.it
}

\author{
Claes Wohlin \\ Blekinge Institute of \\ Technology \\ Ronneby, Sweden \\ claes.wohlin@bth.se
}

\author{
Aybuke Aurum \\ University of New South \\ Wales \\ Sydney, Australia \\ aybuke@unsw.edu.au
}

\author{
Richard Berntsson \\ Svensson \\ Lund University \\ Lund, Sweden \\ rbsv@cs.lth.se
}

\begin{abstract}
Different stakeholders involved in the software development may attribute success to different indicators. Analogously they may support different factors considered the root of successful projects. The study presented in this paper explores how different stakeholders perceive project success and what they deem the effect of specific factors on the project outcome. The study highlighted both commonalities and differences among three main stakeholder classes. A substantial agreement was observed concerning the characteristics that make a project or product successful. As far as the factors that could lead to success are concerned, more bias emerged.
\end{abstract}

Project success factors; strategic view; tactic view; operational view; empirical study

\section{INTRODUCTION}

A software project achieves success by delivering value to various stakeholders - people, groups, or organizations that are actively involved in a project, are affected by its outcome, or can influence its results [20]. In fact a number of studies [4], [7] suggest that it is more effective to measure project success considering stakeholder or business values.

Any stakeholder has his perspective of software development, which depends mainly on his daily tasks, role in the company, artifacts he is working with, and eventually how his work is evaluated. In this research we distinguish three types of the perspectives:

1) Strategic perspective summarizes the views of company's business-oriented stakeholders, i.e. top managers, business analysts, market experts, etc.

2) Tactic perspective represents the views of stakeholders responsible for the daily software development process, mainly project managers.

3) Operational perspective is formed by the views of all those company stakeholders that are directly involved in the product development: developers, testers, system integrators, function analysts, requirement engineers, etc.

Stakeholders of the first group are interested mainly in revenue and customers, since their work is evaluated depending on the returns from the investments and economic benefits for the company. The second group is concerned about schedule and budget; they are judged by delivery precision and project cost. Stakeholders of the third group deal with software artifacts and their work is mainly evaluated upon the quality of the final product.
Thus it is rather obvious that the CHAOS definition of project success "on time and on budget, with all features and functions as originally specified" [9] might not fully reflect opinions of all stakeholders.

Barry Boehm's win-win approach [8] to software management and requirements determination could be applied to project and product evaluation too. The truly successful project would be the one that is considered successful by all stakeholders. So the win-win evaluation is possible when there is a minimal conflict between success factors and characteristics chosen by stakeholders of different perspectives.

Before going further, we introduce the terms used in this work and give some examples. The attributes that are known from the beginning or during the project execution and are controllable by the project team (like requirements collection or risk evaluation) are called project factors. After the project ends it is possible to evaluate its results based on the project characteristics and product characteristics, called also indicators. Project characteristics cover such issues as final evaluation of the resources spent, quality of the teamwork and learning experience. Product characteristics relate mainly to the quality of the final product and its business value.

In order to explain better the win-win approach to the evaluation of project success we use an example. Project managers usually consider "on-time" to be a success indicator. To be on time they might force project members to do extra work. For the developers this extra work might actually obtain the Lister's effect: "people under time pressure don't think faster" [11] and create a stress situation resulting in low quality product - indicator of failure rather than success. In this situation reaching an agreement on what is a successful project and how to ensure it may be complex and could require discussion among the stakeholders.

We expect that an agreement among stakeholders, belonging to different perspectives, on the factors that result in successful projects (or at least these methods are not contradicting), makes it is easier to achieve better teamwork.

Moreover, if the characteristics of successful projects and products are similar (or at least are not incompatible) probably it is easier to have a win-win project/product assessment.

The empirical investigation presented in this paper focuses on the above two issues. It explores what are the success factors and characteristics of software projects and 
products seen from the three stakeholder perspectives and to what extent these criteria are similar.

The paper is organized as follows: section 2 gives an overview of related work. In section 3 we describe the empirical study, including hypothesis formulation, measures and data analysis techniques. Section 4 presents results of data analysis. In section 5 we discuss the findings of the study. In section 6 we address threats to validity. Conclusion and future work are presented in section 7 .

\section{RELATED WORK}

There are many different and overlapping definitions of project success in the literature. A classical definition of project success is: within budget and on time [9]. Lewis [12] defines projects success as meeting performance requirements, cost requirements, time restrictions, and project scope. However, several researchers [5], [13] found that projects success and important factors for project success are perceived differently among different industry domains and different cultures and countries.

It has been suggested that most project managers do not know how to define a successful project or how to characterize project success [13]. A common understanding is that project success is related to project management success and project product success [3], [26]. However, the perception if a project is considered a success or failure depends on the person viewing the project [25]. For example, in Wateridge [25], it was concluded that "to meet user requirements" is the most important success criteria for projects, both for users and project managers. However, the meaning of 'meeting user requirements' is perceived differently. Users associate meeting user requirements with their happiness, while project managers associated it with meeting budget and schedule targets. Moreover, Procaccino and Verner [17] highlight stakeholder differences when they are asked about their perceptions on success of a project.

Others [17], [26] have studied project success and failure factors, which include: user requirements, budget, schedule, quality of the product, delivery time, business goals, and customer satisfaction. While Procaccino et al. [19] found that practitioners consider a success developing software products that meet customer/user needs and are easy to use. Consequently, a project may be considered successful by one stakeholder, but viewed as a failure by another [24].

This indicates that it is needed to consider, not only culture and domains, but also views among different stakeholders, when addressing project success factors.

\section{STUDY DESIGN}

In this section we describe the data collection process, measures and data analysis techniques.

\section{A. Description of Study}

\section{1) Questionnaire}

A quantitative questionnaire [6] was designed to evaluate the research questions. The questions and the possible answers for the closed-end questions were selected during the literature review [6]. Several pilot studies performed to validate the questionnaire. The questionnaire included 33, mostly close-ended questions.
Before the research was conducted in Australia, ethical clearance was received from the University of New South Wales.

The questionnaire consisted of three parts. Part 1 contained questions for gathering background information about the subjects, including data about respondent's position at current company. Part 2 contained close-ended questions about the subjects' last completed software project and open-ended questions about their perception of the success factors. Part 3 contained questions about software products for which the subjects were involved in development. This part contained open-ended questions and a question that allowed participants to assign weights to a series of options. This made it possible for us to ascertain the relative importance of each factor.

\section{2) Data Collection}

Data was collected first from a set of Swedish and Australian companies in 2005 (study referred further as $A u S$ ). The population was software practitioners from Australian and Swedish companies. Software practitioners are defined as software developers (including programmers), database developers, software testers, project and top managers, market analysts, etc. A probability sampling method was used because it provides the researcher with a good selection process of samples from a large known population [2]. Samples were selected through contacts working at companies and from a list of randomly selected software development companies. Two forms for data collection were used: structured interviews and emailed questionnaires. Emailed questionnaires were used to facilitate larger sample sizes and to reduce the time taken for data collection and analysis. There are potential risks with emailed questionnaires, such as lack of interest and time, and a low response rate. Therefore, structured interviews were used to increase the reliability of the data collected [2].

In 2006 the original questionnaire was translated into Italian. The questionnaire was administered, over the period January 2007 to March 2007, using telephone and personal interviews (study referred further as Ita). The selected contacts were software related companies located in northwest of Italy and sampled randomly from the Italian yellow pages database. Most of the respondents were developers, project managers and high-level managers.

Both studies included projects of the following development types: market driven (develop a product for the market), bespoke (customer specific), a mix of bespoke and market driven, and in-house development (developing a product within the same organization).

The replicated study differed from the original one in the design that was used for the second part of the questionnaire. In the first case respondents answered only about one project, successful or failed. In the second study case, respondents answered about both types of projects, successful and failed.

First, the data sets were analyzed separately, [5] and [14]. Since the data in the two studies was collected using very similar questionnaire we were interested to explore the common data set. In this work we discuss the results that come from the analysis of the general-perception 
questions of the questionnaire, which are described in the section 3.B.

\section{B. Hypotheses}

We are primarily interested in identifying the differences in terms of factors and characteristics among stakeholders' views, if any. But before that we must check whether there are clear preferences. If all factors and characteristics were equally important, we would expect a uniform distribution of preferences. We can thus formulate our first high-level null hypothesis:

\section{Respondents value all factors and characteristics of equal importance to achieve project and product success.}

If the above hypothesis can be rejected we can focus on the differences induced by the perspectives and formulate a second high-level null hypothesis:

\section{Relevant characteristics and factors do not vary between respondents with different perspectives.}

\section{Variables and Measures}

In our analysis we will consider a single independent variable: stakeholders' perspectives, which can assume three values: \{strategic, tactic, operational\}. The perspective was defined according to the role played by the respondent:

- strategic: top manager, owner, business analyst, IT market expert, etc;

- $\quad$ tactic: mainly project manager;

- operational: developer, tester, function analyst, requirement engineer, etc.

The dependent variables consist in preferences for factors and characteristics of projects and products, measured as described below.

During the preparation of the Italian questionnaire a few modifications were introduced. Therefore not all items were present in both studies. Items that were present only in the original study are marked by (AuS), while those present only in the replicated study are marked by (Ita).

In addition a context variable was measured: the success or failure of the project, as judged by the respondent.

\section{1) Product Characteristics}

Successful product characteristics help to identify those product features that make it successful. The question was to "consider the produced software product from the project that you just described. Please assess the relative importance of the following factors on the success of the product. You have 1000 points to spend on the different factors." Respondents were given the choice of 8 characteristics, described below:

- Great quality

- $\quad$ Customer satisfied with the product

- Reliability

- The product works

- Economic benefits for the supplier

- Many sold copies

- $\quad$ Satisfied organization/top management

\section{- Good reputation for the supplier}

\section{2) Project Factors}

In this study, by factors we mean those events that may actively contribute to an accomplishment of positive results for any software project. The question was formulated as following: "mark the three (according to you) most important factors for a project to be successful". Respondents could choose among the following 15 factors:

- Understanding the customer's problems

- Customer involvement

- Good relation between personnel

- Good programming (Ita)

- Team experience (Ita)

- $\quad$ Experienced project manager

- Completed and accurate requirements

- Very good project manager

- Well defined communication

- $\quad$ Overall good requirements (AuS)

- Realistic expectations

- Good estimations

- Committed sponsor/champion (AuS)

- Good schedule (AuS)

- Client paid for the project (Ita)

\section{3) Project Characteristics}

There are project features that, observed at the end of the project, indicate the project success. The question was formulated as follows: "mark three characteristics you think are associated with successful projects". Respondents could choose among the following 11 characteristics:

- Met business objective, goal, and user requirements

- Develop new skills (AuS)

- Works in the way it should (AuS)

- Completed on time and within budget

- Completed project

- Met quality requirements

- $\quad$ Technical challenge for you (AuS)

- Learning experience

- Within budget

- Team experience (AuS)

- Develop new functions (Ita)

\section{Data Analysis Techniques}

Since the purpose of our study is mainly explorative, and the nature of the variables renders them very sensitive to small changes, we fixed an $\alpha$-level of $10 \%$ for all statistical tests. Thus our procedure is to reject the null hypotheses when the statistical tests provide a p-value less than $\alpha$-level of $10 \%$.

Hypothesis 1 will be refined for each type of dependent variable and tested with statistical procedure as described in sections 3.D.1 and 3.D.2 below.

As far as hypothesis 2 is concerned, we must consider that the Italian study was not an exact replication of the Australian-Swedish one, but it introduced two main changes:

1) A few factors and characteristics are present in only one of the two studies. 
2) In the Italian study respondents had to mark two project characteristics, and not three like in the original study.

Due to these differences it is impossible to run multivariate tests for the data set. Therefore we will address the second high-level hypothesis by dividing the data set manually into subsets according to the context variable and performing a qualitative analysis.

\section{1) Analysis of Product Characteristics}

The score data are not continuous and are not normally distributed; therefore in principle medians and nonparametric tests should be used.

Unfortunately an initial data analysis showed that respondents typically assigned points to 3-5 characteristics among the eight available. With such data, statistically the median of the points would vary between zero and the lowest scores received by a characteristic. Thus any analysis based on the median would completely disregard most (if not all) the non-zero scores assigned to each characteristic. For this reason we formulate our hypothesis using the mean instead of the median:

H1a_0: the mean of characteristic $Y$ scores is not higher than what would be the result of random score assignment.

To test this null hypothesis the t-test will be used. A random score assignment to all characteristics would lead to a score of $125(1000 / 8)$ for each characteristics. The ttest is generally robust but in this case the conditions for its applicability are not met, therefore its results will be used for explorative purposes only and not conclusive ones.

In addition, the characteristics will be sorted by their total score; then the most popular ones will be analyzed.

\section{2) Analysis of Project Factors and Characteristics}

The first high-level research hypothesis can be refined in the following way:

H1b_0: the frequency of \{factor $X$, characteristic $Y$ \} was not higher than what would be the result of random selection.

In order to analyze if any factor or characteristic was preferred among the others, we will use a one-tail proportion test that allows us to analyze all data points.
In both studies respondents had twelve project factors from which to choose from. Respondents had to select the three most important factors. So the probability for each factor to be chosen in case of random selection was $25 \%$.

In the original study respondents had the choice of ten project characteristics and had to select three of them, while in the replicated study the list of characteristics was made of seven items and only two were requested. So the probability in case or random selection is:

- $30 \%$ for the characteristics asked only in the original study

- $\quad \approx 28,6 \%$ for the characteristics asked only in the replicated study

- $[((3 / 10) * \mathrm{NAuS}+(2 / 7) * \mathrm{NIta}) /(\mathrm{NAuS}+\mathrm{NIta})]^{*} 100$ $\%$ for the characteristics present in both studies, where NAuS and NIta are number of respondents in each study.

Proportion test considers the number of responses and population size. The test examines how far from the expected proportion is the observed proportion. Expected proportion is the probability in case of random selection of a factor.

\section{DATA ANALYSIS}

We received answers from 32 respondents in the Australia-Swedish study and 40 answers from the Italian respondents. In the Table 1 we present numbers of respondents of each view from different countries. The analysis was performed using the R-statistical package ${ }^{1}$.

TABLE II. RESPONDENTS SUMMARY

\begin{tabular}{|l|l|l|l|}
\hline & AuS & Ita & Tot \\
\hline Strategic view & 12 & 8 & 20 \\
\hline Tactic view & 8 & 10 & 18 \\
\hline Operational view & 12 & 22 & 34 \\
\hline
\end{tabular}

\section{A. Product Characteristics}

In this section we present the results of the data analysis for the product characteristics, including the results of H1a_0 tests. In Table 2 significant p-values are printed in bold and the top three characteristics for each view are highlighted.

TABLE II. PRODUCT CHARACTERISTICS

\begin{tabular}{|l|c|c|c|c|c|c|c|c|c|}
\hline & \multicolumn{3}{|c|}{ Strategic view } & \multicolumn{3}{c|}{ Tactic view } & \multicolumn{3}{c|}{ Operational view } \\
\hline \multicolumn{1}{|c|}{ Characteristics } & Mean & $\boldsymbol{O}^{2}$ & $\boldsymbol{p}$-value & Mean & $\boldsymbol{O}$ & $\boldsymbol{p}$-value & Mean & $\boldsymbol{O}$ & $\boldsymbol{p}$-value \\
\hline Great quality & 159 & 2 & $\mathbf{0 , 0 6}$ & 220 & 2 & $\mathbf{0 , 0 4}$ & 125 & 3 & 0,5 \\
\hline Satisfied customer & 247 & 1 & $<\mathbf{0 , 0 1}$ & 320 & 1 & $<\mathbf{0 , 0 1}$ & 318 & 1 & $<\mathbf{0 , 0 1}$ \\
\hline Reliability & 136 & 3 & 0,28 & 102 & 5 & 0,74 & 143 & 2 & 0,13 \\
\hline The product works & 115 & 4 & 0,63 & 135 & 3 & 0,39 & 109 & 4 & 0,8 \\
\hline Economic benefits for the supplier & 100 & 5 & 0,86 & 107 & 4 & 0,73 & 107 & 5 & 0,8 \\
\hline Many sold copies & 98 & 6 & 0,8 & 14 & 8 & 1 & 41 & 8 & 1 \\
\hline Satisfied organization/top management & 75 & 7 & 1 & 55 & 6 & 1 & 78 & 6 & 1 \\
\hline Good reputation for the supplier & 64 & 8 & 0,93 & 47 & 7 & 1 & 60 & 7 & 1 \\
\hline
\end{tabular}


TABLE III. PROJECT FACTORS

\begin{tabular}{|l|c|c|c|c|c|c|c|c|c|}
\hline & \multicolumn{3}{|c|}{ Strategic view } & \multicolumn{3}{c|}{ Tactic view } & \multicolumn{3}{c|}{ Operational view } \\
\hline \multicolumn{1}{|c|}{ Factor } & $\mathbf{\%}^{3}$ & $\boldsymbol{N}^{4}$ & $\boldsymbol{p}$-value & $\boldsymbol{\%}$ & $\boldsymbol{N}$ & $\boldsymbol{p}$-value & $\boldsymbol{\%}$ & $\boldsymbol{N}$ & $\boldsymbol{p}$-value \\
\hline Understanding the customer's problems & 45 & 20 & $\mathbf{0 , 0 3 5}$ & 27,8 & 18 & 0,5 & 41,2 & 34 & $\mathbf{0 , 0 2 4}$ \\
\hline Customer involvement & 40 & 20 & $\mathbf{0 , 0 9 8}$ & 22,2 & 18 & 0,25 & 35,3 & 34 & 0,12 \\
\hline Good relation between personnel & 5 & 20 & 0,96 & 38,9 & 18 & 0,14 & 29,4 & 34 & 0,35 \\
\hline Good programming & 50 & 8 & 0,11 & 30 & 10 & 0,5 & 45,5 & 22 & $\mathbf{0 , 0 2 5}$ \\
\hline Team experience & 25 & 8 & 0,5 & 50 & 10 & $\mathbf{0 , 0 7}$ & 40,9 & 22 & $\mathbf{0 , 0 7}$ \\
\hline Experienced project manager & 15 & 20 & 0,78 & 33,3 & 18 & 0,3 & 23,5 & 34 & 0,5 \\
\hline Completed and accurate requirements & 40 & 20 & $\mathbf{0 , 0 9 8}$ & 22,2 & 18 & 0,25 & 23,5 & 34 & 0,5 \\
\hline Very good project manager & 20 & 20 & 0,6 & 50 & 18 & $\mathbf{0 , 0 1 5}$ & 20,6 & 34 & 0,65 \\
\hline Well defined communication & 25 & 20 & 0,5 & 16,7 & 18 & 0,7 & 20,6 & 34 & 0,65 \\
\hline Overall good requirements & 16,7 & 12 & 0,63 & 12,5 & 8 & 0,66 & 33,3 & 12 & 0,37 \\
\hline Realistic expectations & 25 & 20 & 0,5 & 16,7 & 18 & 0,7 & 11,8 & 34 & 0,94 \\
\hline Good estimations & 20 & 20 & 0,6 & 16,7 & 18 & 0,7 & 8,8 & 34 & 0,98 \\
\hline Committed sponsor/champion & 33,3 & 12 & 0,37 & 12,5 & 8 & 0,66 & 8,3 & 12 & 0,84 \\
\hline Good schedule & 0 & 12 & 0,95 & 0 & 8 & 0,89 & 0,0 & 12 & 0,95 \\
\hline Client paid & 0 & 8 & 0,89 & 0 & 10 & 0,93 & 0,0 & 22 & 0,99 \\
\hline
\end{tabular}

TABLE IV. PROJECT CHARACTERISTICS

\begin{tabular}{|c|c|c|c|c|c|c|c|c|c|}
\hline \multirow[b]{2}{*}{ Characteristic } & \multicolumn{3}{|c|}{ Strategic view } & \multicolumn{3}{|c|}{ Tactic view } & \multicolumn{3}{|c|}{ Operational view } \\
\hline & $\%$ & $N$ & p-value & $\%$ & $N$ & p-value & $\%$ & $N$ & p-value \\
\hline Met business objective, goal, and user requirements & 80,0 & 20 & $<\mathbf{0 , 0 0 1}$ & 66,7 & 18 & $<\mathbf{0 , 0 0 1}$ & 64,7 & 34 & $<0,001$ \\
\hline Develop new skills & 0,0 & 12 & 0,97 & 25,0 & 8 & 0,5 & 8,3 & 12 & 0,9 \\
\hline Works in the way it should & 8,3 & 12 & 0,91 & 25,0 & 8 & 0,5 & 0 & 12 & 0,97 \\
\hline Completed on time and within budget & 70,0 & 20 & $<0,001$ & 55,6 & 18 & 0.014 & 64,7 & 34 & $<0,001$ \\
\hline Completed project & 10,0 & 20 & 0,95 & 5,6 & 18 & 0.97 & 17,6 & 34 & 0,9 \\
\hline Met quality requirements & 50,0 & 20 & 0,04 & 33,3 & 18 & 0.45 & 47,1 & 34 & $\mathbf{0 , 0 1 7}$ \\
\hline Technical challenge for you & 50,0 & 12 & 0,12 & 0,0 & 8 & 0.93 & 25 & 12 & 0,5 \\
\hline Learning experience & 0,0 & 20 & 1 & 16,7 & 18 & 0.82 & 8,8 & 34 & 1 \\
\hline Within budget & 0,0 & 20 & 1 & 5,6 & 18 & 0.97 & 5,9 & 34 & 1 \\
\hline Team experience & 0,0 & 12 & 0,97 & 12,5 & 8 & 0.76 & 0 & 12 & 0,97 \\
\hline Develop new functions & 12,5 & 8 & 0,7 & 10,0 & 10 & 0.83 & 13,6 & 22 & 0,9 \\
\hline
\end{tabular}

More than the half of the most important characteristics is confirmed by the t-test, though we present its results for the exploration purposes and not for the conclusion ones. In section 5 we mainly address the top three chosen characteristics and their order for each of the groups of respondents.

\section{B. Project Factors and Characteristics}

In this section we present the results of the data analysis for the project factors (Table 3 ) and characteristics (Table 4), including the results of H1b_0 tests. Significant $\mathrm{p}$-values are printed in bold.

Developers and other operational-view stakeholders agreed that in order to make successful projects it is necessary to understand customer problems, to have good programming style and team experience.

Project managers believe that most important for project success is to have very good project management and experienced team.

Top managers and other strategic-view stakeholders agreed that complete and accurate requirements, understanding customer problems and his involvement in the project are necessary for the project success.

Respondents of all three groups of stakeholders agreed that meeting business objectives, goals, and user requirements, and completing on time and within budget

Percent of respondents, that chose this factor.

4 Total number of respondents that had this factor as a choice. characterize successful projects. Strategic and operational stakeholders also mentioned meeting quality requirements as one of the most important project characteristics of success.

\section{DISCUSSION}

We have analyzed data from two empirical studies conducted in 2005 in Australia and Sweden and in 2007 in Italy. The small differences between the two studies allowed us to analyze together most of the data. The work presented here first investigates quantitatively which factors and characteristics play the most important role for different stakeholder types in defining success of a software project and product. And second, it compares qualitatively whether these opinions are aligned between them.

Respondents of the study represent all types of stakeholders in a software development organization, including developers, managers, quality engineers, function analysts and so on. Depending on the role played in the company, each respondent was assigned to one of three perspectives: strategic, tactic or operational.

\section{A. Product Characteristics}

There was an agreement between respondents of the three perspectives about two of the most important product characteristics: "customer satisfied with software product" and "great quality". The third indicator of high-quality software in the list was the same for the respondents of 
strategic- and operational-perspectives: both groups chose "reliability" as one of most significant characteristics. Tactic-view stakeholders gave more importance to the characteristic "product works".

Interestingly, product characteristics (reliability and quality) are on the 2-3 top positions even for the strategicperspective respondents; economic issues (e.g. many sold copies or economic benefits) are perceived as less significant.

\section{B. Project Issues}

Factors. Both strategic- and operational-view stakeholders placed "understanding the customer's problems" on the first place. Tactic stakeholders chose "very good project management" as most important factor for the project success.

For both operational and tactic respondents "team experience" plays an important role.

Operational respondents pay special attention to good programming, while strategic respondents consider more important "customer involvement" and "completed and accurate requirements".

Characteristics. The list of most significant characteristics of the successful project is similar for the respondents of the three groups. All respondents evaluated as the most important: "met business objective, goal, and user requirements" and "completed on time and within budget”.

Operational and strategic stakeholders mentioned also the third noteworthy characteristic "met quality requirements", while only $33 \%$ of project-view stakeholders selected it.

In Table 5 we present a summary of the results. Comparing answers of the three groups it seems that there is more agreement between opinions of operational and strategic respondents, than between tactic respondents and stakeholders of any of the other two groups. Probably this is due to the fact that while operational stakeholders develop software, strategic stakeholders sell it, so both groups are concerned about the quality of the final product. Tactic stakeholders are more concerned about administrative issues of the development, since their task is to organize the process and manage the resources.

Besides it seems that while the characteristics of successful projects and products are mostly similar between the groups, the subset of critical project factors is rather different between respondents of different perspectives. It means that there is an agreement on what to consider a successful project or product. But stakeholders of different perspectives give different weight to various methods of how to achieve good results.

\section{THREATS}

The validity of the findings reported is subject to some threats, which can be divided into four main categories: internal, construct, conclusion and external.

Threats to internal validity derive from the possible presence of alternative causes for the observed results. An important threat, in this study, can stem from using inadequate procedures (e.g. the instrument has been changed during data collection) [10]. Between the first and the second study, a translation (form English to Italian) and partial adaptation took place. We analyzed together only perfectly equivalent questions. In addition we adopted a proper analysis method to analyze the project characteristics as described in section 3.D.2. Another threat consists in the different distribution of stakeholders in the two studies: strategic and tactic groups included a comparable number of participants from the two studies. While in the operational group there was a prevalence of Italian developers. We believe that such unbalance does not affect our overall findings; more detailed analysis on the effect of geography is not reported here for lack of space.

Construct validity concerns the correct concrete measurement of abstract concepts. All factors and characteristics, selected for the study, come from different sources, where they all proved to be significant. So we believe that there was no one single "obvious" factor or characteristic, which predominated in the selection with the risk that participants could "guess" the expected answer.

The main threats to conclusion validity are lack of statistical calculations or misuse of statistical assumptions that leads to incorrect conclusions made by the researcher [10]. Proper tests were performed to investigate the

TABLE V. SUMMARY OF THE RESULTS

\begin{tabular}{|c|c|c|c|}
\hline & Strategic view & Tactic view & Operational view \\
\hline $\begin{array}{l}\text { Significant factors of } \\
\text { successful projects }\end{array}$ & $\begin{array}{ll} & \text { Understanding the } \\
\text { - } & \text { customer's problems } \\
\text { - } & \text { Comptomer involvement } \\
& \text { requirements }\end{array}$ & $\begin{array}{ll} & \text { Team experience } \\
- & \text { Very good project } \\
& \text { manager }\end{array}$ & $\begin{array}{ll}- & \text { Understanding the } \\
\text { customer's problems } \\
-\quad \text { Good programming } \\
\text { - } & \text { Team experience }\end{array}$ \\
\hline $\begin{array}{c}\text { Significant } \\
\text { characteristics of } \\
\text { successful projects }\end{array}$ & $\begin{array}{l}\text { Met business objective, } \\
\text { goal, and user } \\
\text { requirements } \\
\text { - Completed on time and } \\
\text { within budget } \\
\text { Met quality } \\
\text { requirements }\end{array}$ & $\begin{array}{ll}\text { - } & \text { Met business } \\
\text { objective, goal, and } \\
\text { user requirements } \\
\text { Completed on time } \\
\text { and within budget }\end{array}$ & $\begin{array}{ll}\text { - } & \text { Met business objective, } \\
\text { goal, and user } \\
\text { requirements } \\
\text { - } \quad \text { Completed on time and } \\
\text { within budget } \\
\text { Met quality } \\
\text { requirements }\end{array}$ \\
\hline $\begin{array}{c}\text { Most important } \\
\text { product characteristics }\end{array}$ & $\begin{array}{ll} & \text { Satisfied customer } \\
- & \text { Great quality } \\
- & \text { (Reliability) }\end{array}$ & $\begin{array}{ll}- & \text { Satisfied customer } \\
- & \text { Great quality } \\
- & \text { (The product works) }\end{array}$ & $\begin{array}{ll}- & \text { Satisfied customer } \\
- & \text { (Great quality) } \\
- & \text { (Reliability) }\end{array}$ \\
\hline
\end{tabular}

Product characteristics indicated in parenthesis were not found statistically relevant 
detailed null hypotheses. The data sample was large enough to perform most of the statistical tests.

Finally, external validity, sometimes referred to as selection validity, is the degree to which the findings can be generalized to other settings. The participants of this study are from three countries: Australia, Italy and Sweden. Companies were randomly selected and vary in size and core business. We believe that our findings can be generalized, to the European and Australian context. Clearly only another replication of this study in a different setting could confute our findings.

\section{CONCLUSIONS}

This paper reports results from an empirical investigation aimed at understanding success factors and characteristics for software projects and products viewed from different perspectives. We distinguish three stakeholders' perspectives: strategic, tactic and operational. We assumed that if the stakeholders of different perspectives agree on the factors that make a successful project it should be easier to run successful projects and produce high-quality software.

72 respondents from Australia, Italy and Sweden participated in the study. We found (see Table 5) that there was an agreement between stakeholders on the definition of what is a successful project and product. In fact the majority of the respondents agreed that "satisfied customer" and "great quality" characterize successful products. As for the project characteristics it was important for all stakeholders that projects "meet business objective, goal, and user requirements" and are "completed on time and within budget".

On the other hand other success factors were quite different in function of the stakeholders' perspectives. For instance, "understanding the customer's problems", is relevant for strategic and operational stakeholders, but not for tactical ones. "Team experience" is relevant for the tactical and operational view, and so on.

The customer perspective is another important key point of view. Our expectation is that it is consistent with the strategic perspective, but this aspect should be investigated in future work.

In conclusion, the findings from this study indicate that success cannot be defined so narrowly as it is done in the chaos report. The formula "on time and on budget, with all features and functions as originally specified" [9] is not sufficient for any of the stakeholders when they talk about successful projects.

\section{ACKNOWLEDGMENT}

We would like to thank all the MSc students for their effort in data collection.

\section{REFERENCES}

[1] Agarwal, N. and Rathod, U. "Defining success for software projects: an exploratory revelation", Int. Journal of Project Manag., 24, pp. 358-370, 2006.

[2] Babbie, E. The Practice of Social Research, Wadsworth, USA, 2004.
[3] Baccarini, D. "The Logical Framework Method for Defining Project Success" Project Management Journal, 30(4) pp. 25-32, 1999.

[4] Barney, S., Aurum, A. and Wohlin, C. "A product management challenge: Creating software product value through requirements selection" Embedded Software Design (JSA) 54(6): 576-593, 2008.

[5] Berntsson Svensson, R. and Aurum, A. (2006) Successful Software Project and Products: An Empirical Investigation, Proceedings of ISESE, pp. 144-153, 2006.

[6] Berntsson-Svensson, R. Successful Software Projects and Products. Master Thesis, Blekinge Institute of Technology, Ronneby, Sweden, 2006.

[7] Boehm, B. "Value-based software engineering: overview and agenda" Value Based Software Engineering, Springer, Berlin, Heidelberg, NY, 2005.

[8] Boehm B.W. and Ross, R. "Theory-W Software Project Management: Principles and Examples", IEEE Trans. Software Eng., pp.902-916, 1989.

[9] CHAOS report http://www.standishgroup.com

[10] Creswell J.W. "Research design", Sage publication, United States of America, 2003.

[11] DeMarco, T. and Lister, T. Peopleware: Productive Projects and Teams. Dorset House, 1999

[12] Lewis, J.P. "Project planning, Schedule, and Control: A Hands-on Guide to Bring Projects in On Time and On Budget”, McGraw-Hill Comp. Inc. USA, 2001.

[13] Linberg, K. "Software developer perceptions about software project failure: a case study." Journal of Systems and Software 49(2-3), 177-192, 1999.

[14] Morisio M., Egorova E. and Torchiano M. "Why software projects fail? Empirical Evidence and Relevant Metrics", Proc. of Mensura, 299-308, 2007.

[15] Pereira, J., Cerpa, N., Verner, J., Rivas, M. and Procaccino, J. "What do software practitioners really think about project success: a cross-cultural comparison", JSS, vol. 81(6), pp. 897-907, 2008.

[16] Pinkerton, W. "Project management: achieving projectbottom line success", McGraw Hill, NY, 2003.

[17] Procaccino, J. and Verner, J. WSoftware practitioner's perception of project success: a pilot study", IJCIM 10(1) pp. 20-30, 2002.

[18] Procaccino, J., Verner, J., Overmyer, S. and Darter, M. "Case study: Factors for early prediction of software development success", ICT, 44(1) 53-62, 2002.

[19] Procaccino, J., Verner, J., Shelfer, K. and Gefen, D. "What do software practitioners really think about project success: an exploratory study", JSS, 78(2) pp. 194-203, 2005.

[20] Smith, L. "Project Clarity Through Stakeholder Analysis", CrossTalk, 13 (12) pp. 4-9, 2000.

[21] Sommerville, I., Sawyer, P. and Viller, S. "Managing process inconsistency using viewpoints", IEEE Trans. Software Eng, 25(6) pp. 784-799, 1999.

[22] Van Der Westhuizen, D. and Fitzgerald, E. "Defining and measuring project success", Proc. ECMLG, 2005.

[23] Verner, J. and Cerpa, N. "Australian Software Development, What Software Project Management Practices Lead to Success?”, Proc. ASWEC05, 70-77.

[24] Walsh, K., Schneider, H. "The role of motivation and risk behavior in software development success." Information Research 7 (3), 2002.

[25] Wateridge, J. "How can IS/IT projects be measured for success", IJPM, 16(1), pp. 59-63, 1998.

[26] [Wohlin, C., von Mayrhauser, A. "Assessing project success using subjective evaluation factors". Journal of Software Quality, 2000. 